\title{
The evolution of the Helsinki frostbite management protocol
}

\author{
Lindford, Andrew
}

2017-11

Lindford, A , Valtonen , J , Hult , M , Kavola , H , Lappalainen , K, Lassila , R , Aho , P \& Vuola , J 2017 , ' The evolution of the Helsinki frostbite management protocol ' , Burns , vol. 43 , no. 7 , pp. 1455-1463 . https://doi.org/10.1016/j.burns.2017.04.016

http://hdl.handle.net/10138/298122

https://doi.org/10.1016/j.burns.2017.04.016

publishedVersion

Downloaded from Helda, University of Helsinki institutional repository.

This is an electronic reprint of the original article.

This reprint may differ from the original in pagination and typographic detail.

Please cite the original version. 


\title{
The evolution of the Helsinki frostbite management protocol
}

\author{
Andrew Lindford ${ }^{a, *}$, Jussi Valtonen ${ }^{a}$, Maarit Hult ${ }^{b}$, Heli Kavola ${ }^{a}$, \\ Kimmo Lappalainen ${ }^{c}$, Riitta Lassila ${ }^{d}$, Pekka Aho $^{e}$, Jyrki Vuola ${ }^{a}$ \\ ${ }^{a}$ Helsinki Burn Centre, Department of Plastic Surgery, Töölö Hospital, Helsinki University Hospital, \\ University of Helsinki, Finland \\ ${ }^{\mathrm{b}}$ Department of Anesthesiology and Intensive Care Medicine, Helsinki University Hospital, University of Helsinki, \\ Helsinki, Finland \\ ${ }^{c}$ Department of Radiology, HUS Medical Imaging Center, Helsinki University Hospital, University of Helsinki, Helsinki, \\ Finland \\ ${ }^{d}$ Coagulation Disorders Unit, Department of Hematology, Helsinki University Hospital, Comprehensive Cancer Center, \\ University of Helsinki, Helsinki, Finland \\ ${ }^{\mathrm{e}}$ Helsinki University Hospital, Abdominal Center, Vascular Surgery, University of Helsinki, Helsinki, Finland
}

\section{A R T I C L E I N F O}

Article history:

Accepted 11 April 2017

Keywords:

Cold injury

Thrombolytic therapy

Amputation

Extremity salvage

\begin{abstract}
A B S T R A C T
Background: Severe frostbite can result in devastating injuries leading to significant morbidity and loss of function from distal extremity amputation. The modern day management approach to frostbite injuries is evolving from a historically very conservative approach to the increasingly reported use of early interventional angiography and fibrinolysis with tPA. The aim of this study was to evaluate the results of our frostbite treatment protocol introduced 3 years ago.

Methods: All frostbite patients underwent first clinical and then Doppler ultrasound examination. Angiography was conducted if certain clinical criteria indicated a severe frostbite injury and if there were no contraindications to fibrinolysis. Intra-arterial tissue plasminogen activator (tPA) was then administered at $0.5-1 \mathrm{mg} / \mathrm{h}$ proximal to the antecubital fossa (brachial artery) or popliteal fossa (femoral artery) if angiography confirmed thrombosis, as well as unfractionated intravenous heparin at 500 units/h. The vasodilator iloprost was administered intravenously $(0.5-2.0 \mathrm{ng} / \mathrm{kg} / \mathrm{min})$ in selected cases.

Results: 20 patients with frostbite were diagnosed between 2013-2016. Fourteen patients had a severe injury and angiography was performed in 10 cases. The total number of digits at risk was 111. Nine patients underwent fibrinolytic treatment with tPA (including one patient who received iloprost after initial non response to tPA), 3 patients were treated with iloprost alone and 2 patients received neither treatment modality (due to contraindications). The overall digital salvage rate was $74.8 \%$ and the Hennepin tissue salvage rate was $81.1 \%$. One patient developed a catheter-site pseudoaneurysm that resolved after conservative treatment. Conclusions: Prompt referral to a facility where interventional radiology and 24/7 laboratory services are available, and the combined use of tPA and iloprost, may improve outcome after severe frostbite.
\end{abstract}

* Corresponding author at: Helsinki Burn Centre, Department of Plastic Surgery, Töölö Hospital, Helsinki University Hospital, Topeliuksenkatu 5, P.O. Box 00029 HUS Helsinki, Finland.

E-mail address: andrew.lindford@hus.fi (A. Lindford).

http://dx.doi.org/10.1016/j.burns.2017.04.016

0305-4179/@ 2017 Elsevier Ltd and ISBI. All rights reserved. 


\section{Introduction}

Cold injuries are comprised of peripheral cold injuries and systemic hypothermia [1]. In Finland peripheral cold injuries are not infrequent with an incidence of 2.5 cases per 100 000 inhabitants, and is more common in men [2]. The yearly incidence in Finland correlates with the environmental temperature and is often associated with alcohol and other psychosocial factors [2-5]. The distal extremities are most commonly affected ( $90 \%$ cases) and the severity of injury ranges from a mild, superficial, reversible condition known as 'frostnip' to a deep tissue freezing injury known as 'frostbite' [6-10]. Severe frostbite can result in devastating injuries leading to significant morbidity and loss of function from frequent distal extremity amputation. Management of frostbite includes rapid rewarming with adequate analgesia. Surgical management of frostbite is delayed to allow full demarcation and to allow maximal recovery of tissues. Traditionally in most institutions the approach has been very conservative with distal amputations an inevitable fate in severe cases and a consequent negative impact on quality of life [4] (Fig. 1). However, over the last 10 years a major therapeutic advance has been made in the early use of fibrinolytic agents to reduce the incidence and morbidity associated with distal extremity tissue loss [11-18]. In addition, the vasodilator drug, iloprost (a synthetic prostacyclin analogue) has been used with some success [19-21].

In an attempt to reduce the morbidity associated with frostbite, in 2013 we introduced the use of fibrinolytics and iloprost for severe frostbite cases at risk of amputation. We herein present our experience using our modified frostbite management protocol.

\section{Patients and methods}

This is a retrospective, observational cohort study of patients admitted with severe frostbite to the Helsinki Burn Centre between 2013 and 2016. Our modified frostbite management protocol is illustrated in Fig. 2. In short, patients with a distal extremity frostbite injury are assessed for severity of injury and clinical signs of ischaemia after initial rapid rewarming. Severe frostbite was defined as a single digit with clinical signs of ischaemia up to the level of, or proximal to, the proximal interphalangeal joint (PIPJ) or interphalangeal joint (IPJ) of the thumb. Involvement of multiple digits with more distal levels of ischaemia was also categorized as severe frostbite. Patients with severe frostbite presenting within $48 \mathrm{~h}$ from injury were then considered for fibrinolytic therapy and after screening for contraindications (as well as a platelet count $>100 \times 10^{9} / \mathrm{L}$ and a haematocrit $>30 \%$ as laboratory parameter prerequisites) to fibrinolytics (Table 2), promptly underwent angiography. Severe hypothermia was considered as only a 'transient' contraindication as it can usually be reversed rapidly, permitting subsequent angiography and possible fibrinolytic therapy.

Diagnostic angiograms were performed via a femoral arterial port and if a clear perfusion defect was seen at the middle phalangeal level (or more distally in multiple digits), fibrinolysis would be indicated. Initially, $3 \mathrm{ml}$ of the vasodilator, papaverine $(50 \mathrm{mg} / 50 \mathrm{ml})$ would be administered slowly to reduce any possible vasospasm. The fibrinolytic drug, alteplase (Actilyse ${ }^{\circledR}$, Boehringer Ingelheim, US) would then be given intra-arterially via the brachial or femoral artery just proximal to the antecubital or popliteal fossae respectively, at a rate of $0.5-1 \mathrm{mg} / \mathrm{h}$ and the dose divided by the number of limbs affected. A bolus of $5 \mathrm{mg}$ per affected limb would be initially administered and the maximum duration would be $12 \mathrm{~h}$ and a check angiogram would be performed at this stage or earlier depending on the clinical situation. Unfractionated heparin was also concurrently infused intravenously to prevent the formation of new clots and the propagation of existing thrombi, and the rate adjusted to the Activated Partial Thromboplastin Time (APTT) accordingly. Patients were monitored on the Intensive Care unit. Following the completion of fibrinolysis, low molecular weight heparin (enoxaparin $40 \mathrm{mg}$ bd sc) (Klexane ${ }^{\mathbb{R}}$, Sanofi, Paris, France) would be commenced $2-4 \mathrm{~h}$ after removal of the arterial port.

Intravenous iloprost (Ilomedin ${ }^{\mathbb{R}}$, Bayer AG, Leverkusen, Germany) was considered in the event of contraindications to

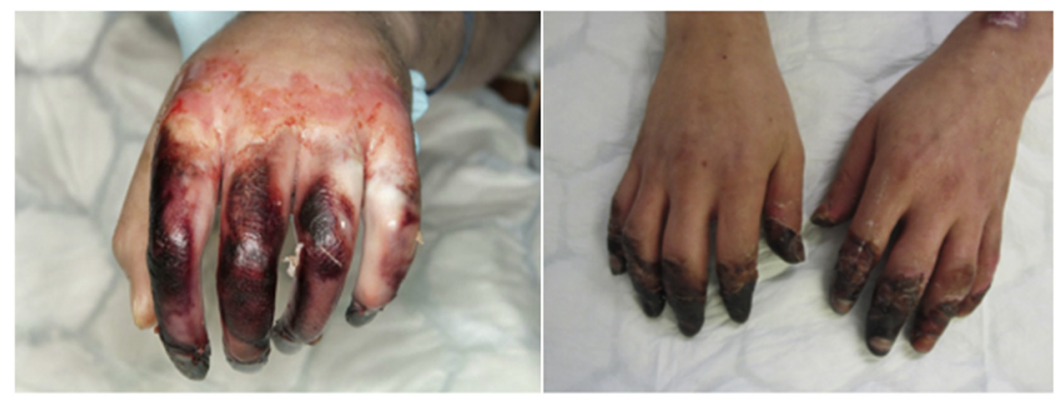

Fig. 1 - Two cases of severe frostbite with digital necrosis. 


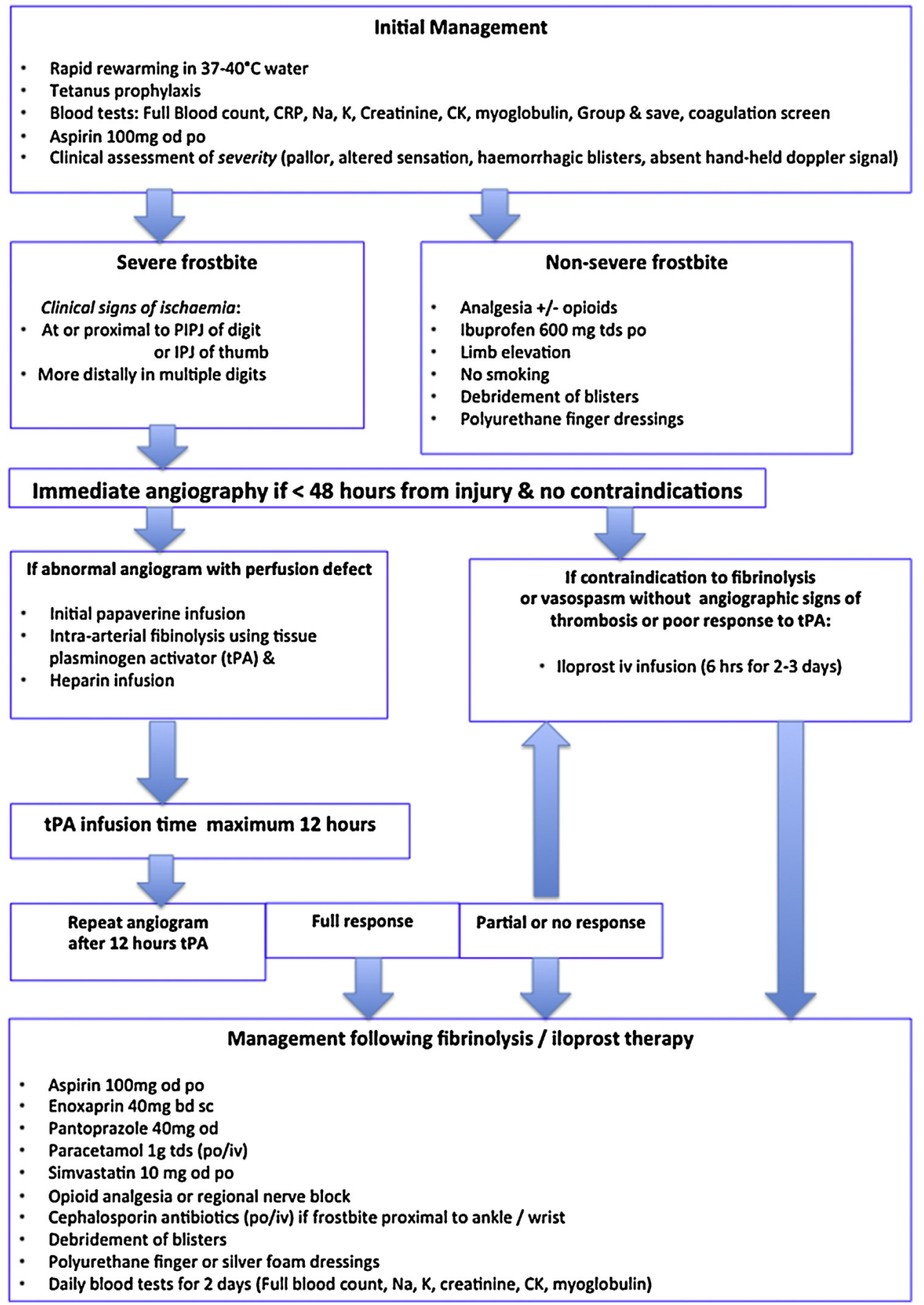

Fig. 2 - Helsinki frostbite management protocol.

fibrinolysis or suspected vasospasm without thrombosis on angiography. Iloprost was administered at an initial rate of $0.5 \mathrm{ng} / \mathrm{kg} / \mathrm{min}$ and gradually increased at $30 \mathrm{~min}$ intervals to a maximum of $2.0 \mathrm{ng} / \mathrm{kg} / \mathrm{min}$. The duration of infusion would be $6 \mathrm{~h}$ per every $24 \mathrm{~h}$ period for 2-3 days. The patients would be cardiac monitored on a high-dependency unit for the duration of iloprost therapy. Our protocol evolved during the course of the study to also consider iloprost in the event of a poor response to fibrinolysis.
Data were collected on patient demographics, time from injury to presentation, core temperature at admission, medical comorbidities, psychosocial risk factors for frostbite, length of hospital stay, location and extent of injuries, angiographic findings, results of fibrinolysis, number of digits amputated, level of amputations and the number of joints salvaged. We used the recently reported Hennepin Score as a means to better illustrate the extent of injury and results of intervention by quantification of the injury and 
Table 1 - Frostbite patient demographics, intervention and outcome.

\begin{tabular}{|c|c|}
\hline & $\mathrm{N}=20$ \\
\hline Age (years), mean (range) & $51.1(19-77)$ \\
\hline Male gender (\%) & $16(80 \%)$ \\
\hline Hypothermia $\left(<35^{\circ} \mathrm{C}\right)$ at presentation & $7(35 \%)$ \\
\hline Social risk factors ${ }^{a}$ & $15(75 \%)$ \\
\hline Comorbidities $^{\mathrm{b}}$ & $8(40 \%)$ \\
\hline Presentation $<24 \mathrm{~h}$ since injury & $12(60 \%)$ \\
\hline \multicolumn{2}{|l|}{ Extremity } \\
\hline - Upper & $12(60 \%)$ \\
\hline - Lower & $6(30 \%)$ \\
\hline - Both & $2(10 \%)$ \\
\hline $\begin{array}{l}\text { Clinical signs of severe injury (Consideration } \\
\text { for fibrinolysis/iloprost) }\end{array}$ & $14(70 \%)$ \\
\hline \multicolumn{2}{|l|}{ Intervention } \\
\hline Angiography & 10 \\
\hline Mean no. of digits at risk per patient & $7.9^{c}$ \\
\hline Fibrinolysis (tPA) ${ }^{\mathrm{d}}$ & 9 \\
\hline Iloprost only & 3 \\
\hline No tPA or iloprost & 2 \\
\hline \multicolumn{2}{|l|}{ Response to tPA } \\
\hline - Full & 5 \\
\hline - Partial & 3 \\
\hline - No & 1 \\
\hline \multicolumn{2}{|l|}{ Outcome } \\
\hline No. of patients undergoing amputation(s) & 6 \\
\hline No. of joints salvaged per patient & 7.9 \\
\hline Overall digital salvage rate & $74.8 \%$ \\
\hline \multicolumn{2}{|l|}{ Hennepin score (22) } \\
\hline - At risk & 12.7 \\
\hline - Amputated & 3.3 \\
\hline - Salvage & 10.2 \\
\hline Overall Hennepin salvage rate & $81.1 \%$ \\
\hline Mean length of stay (days) & 6.7 \\
\hline \multicolumn{2}{|c|}{$\begin{array}{l}\text { a Social risk factors: alcohol abuse, drug abuse, pyschiatric illness, } \\
\text { smoking. } \\
\text { b Comorbidities: acute pancreatitis, hepatitis C, diabetes, dyslipide- } \\
\text { mia, Parkinson's disease, Alzheimer's disease. } \\
\text { c Includes whole foot in } 1 \text { case. } \\
\text { d Includes } 1 \text { case of additional iloprost after no initial response to } \\
\text { tPA. }\end{array}$} \\
\hline
\end{tabular}

\section{Table 2 - Contraindications to fibrinolytic therapy [38].}

Contraindications to fibrinolytic therapy

\begin{tabular}{ll}
\hline Absolute & Relative \\
\hline - >48h from injury & - Transient ischaemic attack within 6 months \\
- Bleeding diathesis & • Uncontrolled hypertension $>180 / 110$ mmHg \\
- Major trauma, head injury or surgery within 3 weeks & - Current therapeutic anticoagulation (e.g. warfarin) \\
- Previous haemorrhagic stroke & - Current gastric ulcer \\
- Cerebral infarct or subarachnoid haemorrhage within 6 months & - Chronic liver disease \\
- Brain tumour, AV malformation or untreated cerebral aneurysm & • Pregnancy or childbirth within 1 month \\
- Gastrointestinal haemorrhage within 1 month & - Infective endocarditis \\
- Suspected aortic dissection & - Freeze-thaw-refreeze injury \\
- Recent deep biopsies (e.g. liver) that cannot be compressed & - Severe hypothermia \\
& - Prolonged resuscitation \\
\hline
\end{tabular}

tissue loss [22]. Our adaptation of the Hennepin Score involved the retrospective analysis of clinical and angiographic findings and from these scores we could then calculate the overall \% salvage rate.

\section{Results}

A cohort of 20 consecutive patients who presented to the Helsinki Burn Centre with frostbite between 2013 and 2016 (three winter seasons) was included in this study. The demographics of this group of patients are shown in Table 1. Social risk factors associated with frostbite could be identified in $75 \%$ patients with alcohol abuse being the most frequent factor found in 9 cases. Six of the 20 patients were diagnosed with a superficial frostbite injury and had no clinical signs of ischaemia (Fig. 3). They were managed with conservative therapy alone, according to our protocol outlined in Fig. 2. There were no cases of amputation in the superficial frostbite group. The remaining 14 patients diagnosed with a severe cold injury were considered for interventional therapy. Ten of these severe cases had involvement of both upper $(n=7)$ or both lower $(n=3)$ extremities and the remainder only a single extremity. Ten patients underwent extremity angiography. The total number of digits at risk was 111 and the mean number of digits at risk per patient was 7.9. This included one patient with a severe injury resulting in ischaemia of the lower extremity up to the ankle level.

Four patients had contraindications for angiography and fibrinolysis, including significant comorbidities in two cases (acute pancreatitis, pneumonia and atrial fibrillation in one case and abnormal hepatic and renal function in the other) and delayed presentation $(>48 \mathrm{~h})$ in the other two cases.

In 9 out of 10 cases perfusion defects were seen on angiography, and fibrinolysis was subsequently administered. In the other case, angiographic findings supported a diagnosis of vasospasm and iloprost was therefore administered. The duration of tissue Plasminogen Activator (tPA) infusion was $12 \mathrm{~h}$ in all cases and the total tPA administered ranged from 15 to $22 \mathrm{mg}$. Of the 4 patients who had contraindications for angiography and fibrinolysis, 2 cases underwent treatment with iloprost alone and the other 2 patients received neither treatment modality due to presentation $72 \mathrm{~h}$ from injury in one 


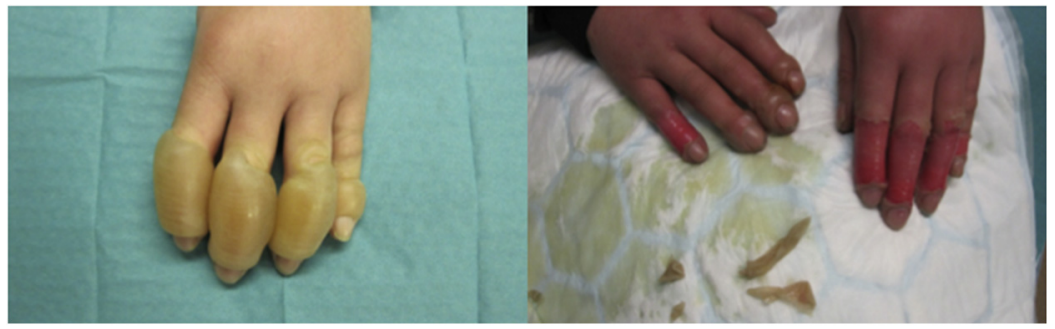

Fig. 3 - Superficial frostbite with debridement of clear fluid-filled blisters.

case and significant comorbidities (including cardiac arhythmias) in the other. Table 1 lists the treatment and outcome results for severe frostbite. A full response to tPA was defined as restoration of distal blush on final angiogram (Fig. 4A and B). A partial response was defined as a perfusion defect/blockage more distal compared to the initial angiogram (Fig. 4C). No response referred to the absence of improvement in distal circulation on angiogram.

Of the 9 patients treated with tPA (Table 3), 8 had a full or partial response. Overall, 6 patients underwent at least one digital amputation and a mean of 7.9 joints were salvaged per patient. The overall digital salvage rate (total number of digits at risk minus number of digits amputated divided by total number of digits at risk multiplied by 100 ) was $75 \%$. The application of the Hennepin score resulted in an overall tissue salvage rate of $81 \%$ for all severe cases of frostbite. Three patients (patients 1, 3 and 4) exhibited a full response to tPA and the salvage rate was $100 \%$ (Fig. $4 \mathrm{~A}$ and B). Two patients (patients 2 and 7) attained a near complete response to tPA and achieved a combined digital salvage rate of $95 \%$. These 2 patients were fibrinolysed within $24 \mathrm{~h}$ from injury. Two patients had a poor response to tPA in spite of expedient initiation of fibrinolysis. These included the patient with a selfinflicted frostbite injury caused by submersion of her foot in dry ice for $6 \mathrm{~h}$ (patient 5). She went on to receive a below knee amputation. The other patient had a minimal response to tPA, but had complete reperfusion after iloprost infusion (patient 9). For the 2 patients (patients 6 and 8) presenting greater than
A
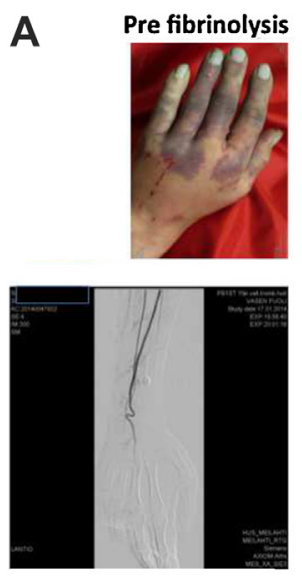

C
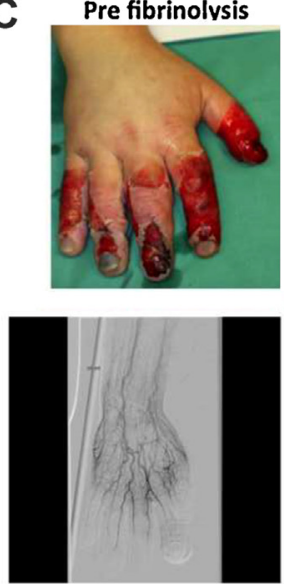
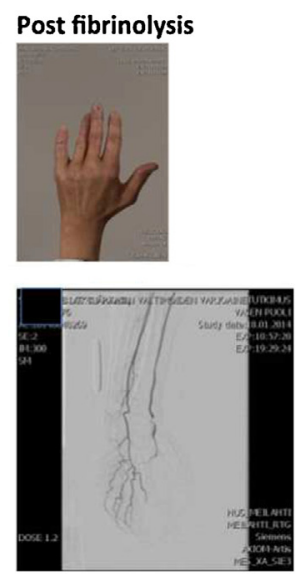

Post fibrinolysis

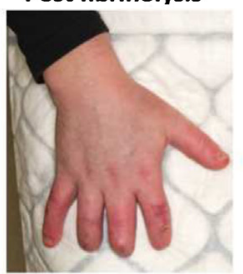

B
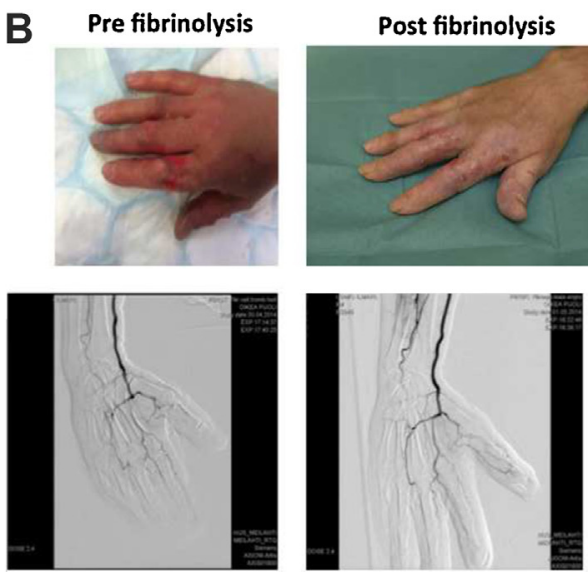

Post fibrinolysis
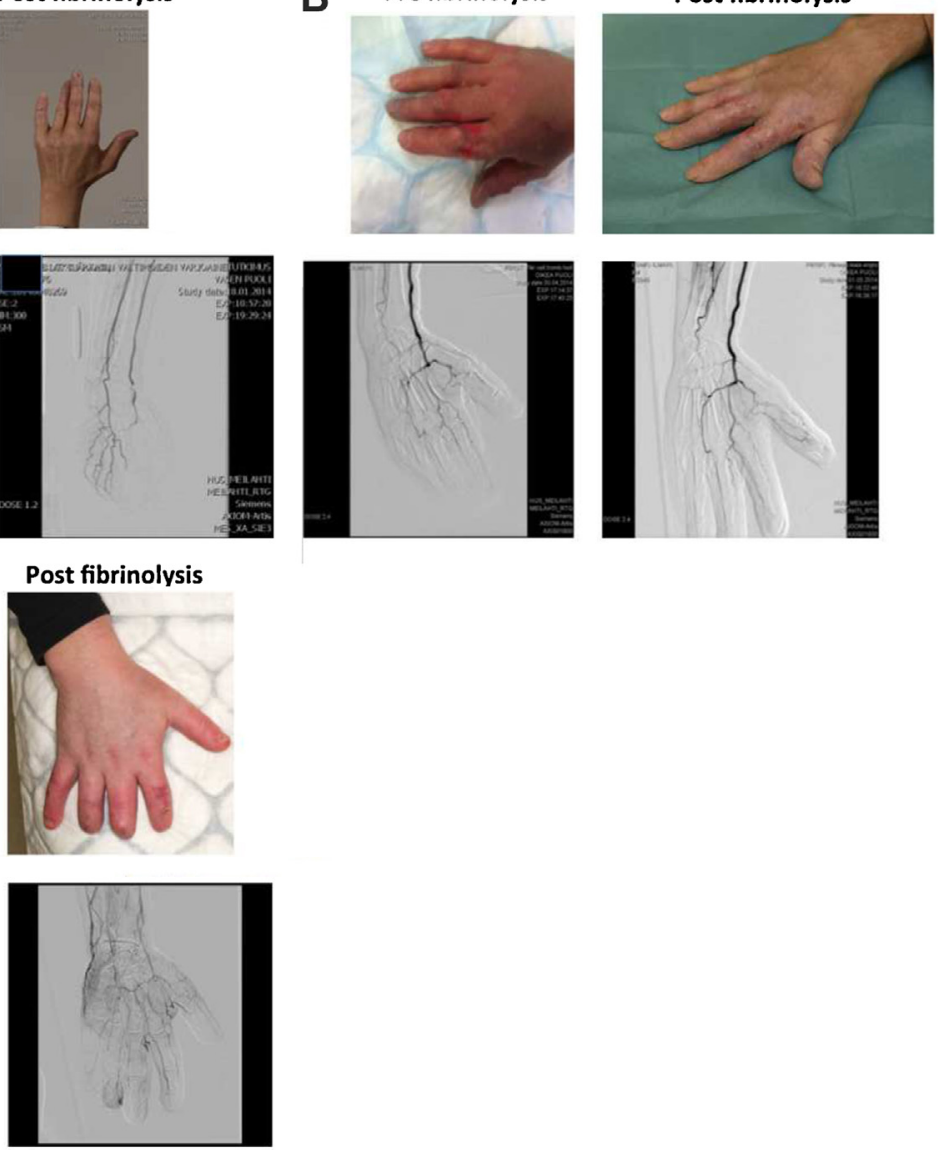

Fig. 4-Clinical and angiographic findings pre and post fibrinolysis in 3 patients with severe frostbite Fig. 4A and B illustrate a full response to tPA (patients 1 and 3), Fig. 4C illustrates a partial response to tPA (patient 8). 
Table 3 - Outcome after treatment with fibrinolytic therapy.

\begin{tabular}{|c|c|c|c|c|c|c|c|c|c|}
\hline Patient number & 1 (Fig. 4A) & 2 & 3 (Fig. 4B) & 4 & 5 & 6 & 7 & 8 (Fig. 4C) & 9 \\
\hline Age (years) & 59 & 72 & 62 & 19 & 22 & 77 & 42 & 49 & 58 \\
\hline Gender & Male & Male & Male & Male & Female $^{a}$ & Male & Male & Male & Male \\
\hline $\begin{array}{l}\text { Time to thawing } \\
\text { (hrs) }\end{array}$ & 6 & 12 & 1 & 5 & 6 & 25 & 5 & 32 & 8 \\
\hline $\begin{array}{l}\text { Thawing } \\
\text { mechanism }\end{array}$ & $\begin{array}{l}\text { Warm wa- } \\
\text { ter } 30 \mathrm{~min}\end{array}$ & $\begin{array}{l}\text { Warm water } \\
30 \mathrm{~min}\end{array}$ & Warm shower & $\begin{array}{l}\text { Warm } \\
\text { water } \\
45 \mathrm{~min}\end{array}$ & Warm water $30 \mathrm{~min}$ & None & Warm water $30 \mathrm{~min}$ & None & $\begin{array}{l}\text { Warm water } \\
30 \mathrm{~min}\end{array}$ \\
\hline Smoking (yes/no) & Yes & No & No & No & No & No & No & No & No \\
\hline $\begin{array}{l}\text { Concomitant } \\
\text { medication }\end{array}$ & None & ACE inhibitor & Statin & None & $\begin{array}{l}\text { Testosterone } \\
\text { Moclobemide }\end{array}$ & Bisoprolol Tamsumin & None & None & Paliperidone \\
\hline $\operatorname{Limb}(\mathrm{s})$ affected & Both hands & Both hands & Right hand & Both feet & Right foot & Both hands & Both hands & Both hands & Right foot \\
\hline No. of digits at risk & 10 & 10 & 3 & 10 & 5 , foot & 10 & 10 & 10 & 5 \\
\hline $\begin{array}{l}\text { Hennepin 'at- risk' } \\
\text { score (R) }\end{array}$ & 20 & 4 & 3 & 10 & 20 & 16 & 15 & 18 & 59 \\
\hline $\begin{array}{l}\text { Time from injury to } \\
\text { tPA (hours) }\end{array}$ & 9 & 18 & 6 & 8 & 8 & 27 & 8 & 35 & 14 \\
\hline $\begin{array}{l}\text { Total tPA dose \& } \\
\text { duration }\end{array}$ & $22 \mathrm{mg}, 12 \mathrm{~h}$ & $22 \mathrm{mg}, 12 \mathrm{~h}$ & $17 \mathrm{mg}, 12 \mathrm{~h}$ & $22 \mathrm{mg}, 12 \mathrm{~h}$ & $17 \mathrm{mg}, 12 \mathrm{~h}$ & $22 \mathrm{mg}, 12 \mathrm{~h}$ & $22 \mathrm{mg}, 12 \mathrm{~h}$ & $22 \mathrm{mg}, 12 \mathrm{~h}$ & $15 \mathrm{mg}, 12 \mathrm{~h}$ \\
\hline $\begin{array}{l}\text { Total dose \& timing } \\
\text { of iloprost? }\end{array}$ & NA & NA & NA & NA & NA & NA & NA & NA & $\begin{array}{l}0.108 \mathrm{mg} \text {, } \\
\text { started } 2 \mathrm{~h} \text { af- } \\
\text { ter tPA } \\
\text { completion }\end{array}$ \\
\hline $\begin{array}{l}\text { Final distal level of } \\
\text { perfusion }\end{array}$ & Digital tips & $\begin{array}{l}\text { Digital tips } \\
\text { except little } \\
\text { finger (mid } \\
\text { middle } \\
\text { phalanx) }\end{array}$ & Digital tips & Digital tips & $\begin{array}{l}\text { Single vessel (peroneal) } \\
\text { flow to forefoot only }\end{array}$ & $\begin{array}{l}\text { Right hand - mostly DIPJ level. Left } \\
\text { hand - mostly PIPJ level }\end{array}$ & $\begin{array}{l}\text { Both hands- digital } \\
\text { tips/DIPJ level }\end{array}$ & $\begin{array}{l}\text { Right — vari- } \\
\text { able, PP-DIPJ } \\
\text { levels. Left - } \\
\text { digital tips/MP } \\
\text { level }\end{array}$ & $\begin{array}{l}\text { Metatarsal } \\
\text { level only after } \\
\text { tPA, clinically } \\
\text { full distal per- } \\
\text { fusion after } \\
\text { iloprost }\end{array}$ \\
\hline $\begin{array}{l}\text { No. of digits } \\
\text { amputated }\end{array}$ & 0 & 1 & 0 & 0 & Below-knee amputation & 9 & 0 & 4 & 0 \\
\hline $\begin{array}{l}\text { Hennepin } \\
\text { 'amputated' score } \\
\text { (A) }\end{array}$ & 0 & 0.5 & 0 & 0 & 20 & 13 & 0 & 2 & 0 \\
\hline $\begin{array}{l}\text { No. of digits } \\
\text { salvaged }\end{array}$ & 10 & 9 & 3 & 10 & 0 & 1 & 10 & 6 & 5 \\
\hline $\begin{array}{l}\text { Overall digital } \\
\text { salvage rate (\%) }\end{array}$ & $100 \%$ & $90 \%$ & $100 \%$ & $100 \%$ & $0 \%$ & $10 \%$ & $100 \%$ & $60 \%$ & $100 \%$ \\
\hline $\begin{array}{l}\text { Hennepin 'salvage' } \\
\text { score }(S)=R-A\end{array}$ & 20 & 3.5 & 3 & 10 & 0 & 3 & 15 & 16 & 59 \\
\hline $\begin{array}{l}\text { Hennepin salvage } \\
\text { rate } \%=(S / R) \times 100\end{array}$ & $100 \%$ & $87.5 \%$ & $100 \%$ & $100 \%$ & $0 \%$ & $18.8 \%$ & $100 \%$ & $88.9 \%$ & $100 \%$ \\
\hline
\end{tabular}


$24 \mathrm{~h}$ from injury, only a modest response to tPA was achieved (10 and 60\% digital salvage rate respectively) (Fig. 4C).

For the 4 patients treated with iloprost (including the patient who had an absent response to tPA) the salvage rate was $78 \%$. Of note, one patient who was treated with iloprost had a salvage rate of only $11 \%$. This patient had presented $>24 \mathrm{~h}$ from injury. Interestingly, one of the two patients who received neither tPA nor iloprost had a salvage rate of $100 \%$. This can perhaps be accounted for by the fact that this patient had a limited duration of cold exposure $(<3 \mathrm{~h})$ and swift initiation of thawing in warm water for $30 \mathrm{~min}$, supporting the endogenous fibrinolytic response. There were two complications associated with fibrinolysis in which a patient developed both a femoral catheter-site pseudoaneursym and a right elbow subcutaneous haematoma. These were successfully treated with conservative management. No problems were encountered with the use of iloprost.

\section{Discussion}

Frostbite injuries have been well described over the past two centuries affecting mostly military personnel. In more recent times there has been an increase in reported civilian cases in populations exposed to cold winters and also amongst alpine climbers $[1,2,4,5]$. Frostbite frequently occurs in healthy adults and can lead to significant morbidity from extremity amputation in severe cases. Although the distal extremities are most commonly affected, the shins, cheeks, nose, ears, and corneas may also be injured [6,9]. The severity is related to the environmental temperature and more importantly to the duration of exposure. Risk factors for frostbite include many psychosocial and environmental factors (drug misuse, especially alcohol, psychiatric illness, homelessness, sporting or military activities), certain medical conditions such as peripheral vascular disease, trauma and male gender [2-10].

The modern day approach to frostbite has changed from a very conservative approach to a modern day approach involving the use of fibrinolytic therapy as reported in several North American centres [11-18] and iloprost in some European centres $[19,20]$. We herein presented the results of our protocol introduced 3 years ago incorporating the use of both treatment modalities. Unfractionated heparin was administered for the duration of the fibrinolysis and until removal of the arterial port, and then followed by enoxaparin for 2 weeks. We report a tissue salvage rate of $81 \%$ (using the 'Hennepin score') in severe cases of frostbite and this figure compares well with reported rates of $66-78 \%[18,22]$ from the Hennepin County Medical Center, Minneapolis. The recently reported Hennepin Score is a useful tool to quantify the extent of the frostbite injury and more accurately compare salvage rates in a standardized manner [22]. The Hennepin score does not, however, improve the prediction of amputation, but does allow quantification of what the accuracy of the prediction was. The recent report by Gonzaga et al., from the Burn Center, Regions hospital, Minnesota, USA, presented a digital salvage rate of $69 \%$. This is also comparable to our own digital salvage rate of $75 \%$. However, it should be noted that the aforementioned studies had significantly larger study groups than ours. In addition, our use of the Hennepin Score depended on the retrospective assessment of clinical and angiographic findings, as opposed to perfusion defects on triple-phase bone scan assessment [22].

Historically, frostbite was classified in a similar way to thermal burns with a first degree injury affecting the epidermis only, second and third degree injuries associated with blistering (containing clear and haemorrhagic fluid, respectively) and a fourth degree injury penetrating the deeper structures with resultant tissue loss [23]. However, in view of the heterogeneity of frostbite lesions, we found this classification unhelpful in predicting prognosis. More critical is the assessment of distal perfusion by examining for signs of ischaemia, and we use a hand-held Doppler as an adjunct to clinical examination. We defined a 'severe' injury as the demonstration of ischaemia at the level of, or proximal to the proximal interphalangeal joint in a single digit or more distally if multiple digits or the thumb are involved. A similar staging system was proposed by Cauchy et al. in 2001 that describes the proximal level of cyanosis after rewarming and assigns a grade, from 1 to 4 [24]. A grade 3 lesion would be characterized by cyanosis up to the metacarpophalangeal joint and would be predicted to have a high risk of amputation. Gonzaga et al. described poor prognostic signs (within $12 \mathrm{~h}$ after rewarming) to comprise: cool skin, numbness, cyanotic digits without blisters and only proximal blisters with haemorrhagic fluid [17]. These patients in the latter study would then be considered for angiography in their protocol.

The initial management of frostbite consists of the appropriate management of hypothermia, trauma or any unstable comorbidities, if present. Thereafter, the acute treatment for all frostbitten extremities is their rapid rewarming in water heated to $37-40^{\circ} \mathrm{C}$ with a mild antibacterial agent (povidone-iodine or chlorhexidine) added for at least $30 \mathrm{~min}$ until complete thawing [25]. Rewarming should only be performed once there is no risk of further refreezing $[6-9,23,25]$. Parenteral opioid analgesia is often used for pain during rewarming and massage of the affected extremity is not recommended [6]. The scientific evidence for much of the described after rewarming management is variable in terms of methodological quality [25]. There is controversy regarding blister management, whether or not to debride. We tend to debride both clear (more superficial injury) and haemorrhagic (deeper injury) blisters as we feel this helps in the initial assessment and wound care. Elevation of the affected extremity is important to reduce oedema. Many have traditionally advocated the application of aloe vera gel to the affected areas in view of its theoretical antivasospastic prostaglandin effect. This proved very labour intensive as recommendations advised up to 6 applications per day, therefore our current protocol involves the use of simple polyurethane foam finger or silver-based foam dressings after blister debridement. Prophylactic antibiotics are not proven but advisable for more severe/extensive injuries. Smoking should be strictly prohibited for obvious reasons. Tetanus toxoid should be administered even though frostbite is generally not a tetanus-prone wound. Systemic nonsteroidal anti-inflammatory drugs should be administered but there is some disagreement whether ibuprofen or aspirin is more beneficial. We have opted for aspirin $100 \mathrm{mg}$ od alone in view of its more potent antiplatelet effects. Furthermore, it has been demonstrated that the concomitant administration of 
ibuprofen antagonizes the irreversible platelet inhibition induced by aspirin [26]. Furthermore, enoxaparin provides an anti-inflammatory as well as anticoagulant effect, and was administered together with aspirin. Early mobilisation of injured extremities is also important to preserve function.

Short-term complications include compartment syndrome, infection, and ischaemia of the distal extremities, with potential tissue necrosis and tissue loss. Long-term sequelae include cold sensitivity, sensory loss, hyperhidrosis, chronic pain and loss of function associated with distal amputation $[6,8,9]$. Surgery is not usually indicated in the acute phase and should be delayed until the frostbitten area is thoroughly demarcated. However fasciotomy may be indicated in cases of compartment syndrome and early amputation in cases of sepsis [10].

Imaging forms an important part of the initial management for assessment of prognosis and likelihood of distal necrosis. Although many different imaging modalities have been suggested, angiography and technetium 99 bone scanning are the most useful prognostically $[15,27,28]$.

Numerous adjuvant therapies have been proposed but many lack strong scientific evidence for their use. These include: hyperbaric oxygen therapy described in a few case reports [29-31], surgical or chemical sympathectomy [32-34] and pentoxifylline, a phophodiesterase inhibitor $[35,36]$. The latter drug was formerly our adjuvant therapy of choice before adopting the new protocol.

After careful discussions and collaboration with a multidisciplinary group of specialists from plastic surgery, interventional radiology, anaesthesia, vascular surgery and haematology we elected to adopt the use of fibrinolytics in our frostbite protocol. The successful use of fibrinolytics is increasingly being reported in the literature [11-18] with most centres favouring intra-arterial tPA administration. Due to the procoagulant effects subsequent to fibrinolysis, coadministration of heparin (unfractionated or low molecular weight) is necessary $[37,38]$ It is generally agreed that tPA is most effective within $24 \mathrm{~h}$ from injury and a recent study demonstrated that for each hour delay in fibrinolytic therapy, a $28 \%$ decrease in the salvage rate is recorded [18]. As many of our patients present late we extended this time limit to up to $48 \mathrm{~h}$ in the hope that for severe cases at least a partial response to treatment could be achieved to preserve function. This was observed in two of our patients with delayed presentation. After discussion with our multidisciplinary team and riskbenefit assessment we opted to limit our maximum tPA infusion duration to only $12 \mathrm{~h}$ in order to reduce the risk of haemorrhagic complications. This is in contrast to the protocol of Gonzaga et al. who have a maximum infusion period of $72 \mathrm{~h}$. The factors resulting in a poor response to tPA in our study consisted of: late presentation $>24 \mathrm{~h}$, prolonged contact exposure to dry ice and a predominance of vasospasm. It should be noted that prolonged exposure to dry ice results in a very rare type of flash freeze injury, not actual frostbite. Whereas frostbite results from slow cooling, similar to controlled tissue cryopreservation, and is potentially reversible, a flash-freeze injury results from extremely rapid cooling, where large intracellular ice crystals form quickly and cause cellular rupture [39]. These injuries do not respond to thrombolytic therapy [17].
Instead of prolonged tPA infusions we currently favour the addition of iloprost (along with enoxaparin) if only a partial response is seen initially with tPA. Iloprost, a synthetic prostacyclin analogue, is a vasodilatory drug that has also been used with success [20]. In fact, the latter study by Cauchy et al. is the only randomized controlled trial to date comparing different adjuvant frostbite therapies. Iloprost is clearly advantageous over tPA in its much superior safety profile and in not an indication for intensive care monitoring or collaboration with an interventional radiology department. However, it only has a short mode of action. The key issue when assessing frostbite is to determine whether there is predominantly thrombosis that would warrant tPA or mainly vasospasm that would benefit from the use of a vasodilator such as iloprost. Our protocol has evolved to include both tPA and iloprost, whereby the latter offers a 'completion' therapeutic option in case of partial or no response to tPA. Iloprost alone is also administered if there are contraindications to fibrinolysis. We also included pantoprazole in our post fibrinolysis management protocol in view of its gastrointestinal protective effect with concurrent aspirin therapy. Simvastatin was included for its endothelium-protecting and other pleiotropic effects.

Clearly, a major limitation of this study is the small study size and therefore we are currently planning a multicentre combined Nordic study to further assess the role of iloprost and tPA.

\section{Conclusion}

In conclusion, prompt referral to a facility where interventional radiology and 24/7 laboratory services are available, and the combined use of tPA and iloprost, may improve outcome after severe frostbite. Further multicentre trials, including ibomarker follow-up, are, however, warranted before this still experimental treatment modality can be considered as standard of care in severe frostbite.

\section{Source of funding}

This research received a grant from the Finnish-Norwegian Medical Foundation (Suomalais-Norjalainen Lääketieteen Säätiö).

\section{Conflict of interest statement}

The authors declare that there are no conflicts of interest.

R E F E R E N C E S

[1] Cochran A, Morris SE, Saffle JR. Cold-induced injury: frostbite. In: Herndon DN, editor. Total burn care. 4th ed. London: Saunders; 2012. p. 449-53.

[2] Juopperi K, Hassi J, Ervasti O, Drebs A, Nayha S. Incidence of frostbite and ambient temperature in Finland, 1986-1995: A 
national study based on hospital admissions. Int J Circumpolar Health 2002;61:352-62.

[3] Kyösola K. Clinical experiences in the management of cold injuries: a study of 110 cases. J Trauma 1974;14 (January (1)):32-6.

[4] Koljonen V, Andersson K, Mikkonen K, Vuola J. Frostbite injuries treated in the Helsinki area from 1995 to 2002. J Trauma 2004;57:1315-20.

[5] Antti-Poika I, Pohjolainen T, Alaranta H. Severe frostbite of the upper extremities - a psychosocial problem mostly associated with alcohol abuse. Scand J Soc Med 1990;18(1):59-61.

[6] Murphy JV, Banwell PE, Roberts AH, McGrouther DA. Frostbite pathogenesis and treatment. J Trauma 2000;48:171-8.

[7] Imray C, Grieve A, Dhillon S. Caudwell Xtreme Everest Research Group. Cold damage to the extremities: frostbite and non-freezing cold injuries. Postgrad Med J 2009;85:481-8.

[8] Hallam MJ, Cubison T, Dheansa B, Imray C. Managing frostbite. BMJ 2010;341:c5864.

[9] Mohr WJ, Jenabzadeh K, Ahrenholz DH. Cold injury. Hand Clin 2009;25:481-96.

[10] Lindford AJ, Vuola J. Helsinki -20 degrees C. BMJ 2011;343: d8020.

[11] Twomey JA, Peltier GL, Zera RT. An open-label study to evaluate the safety and efficacy of tissue plasminogen activator in treatment of severe frostbite. J Trauma 2005;59 (December (6))1350-4 discussion 1354-5.

[12] Bruen KJ, Ballard JR, Morris SE, Cochran A, Edelman LS, Saffle JR. Reduction of the incidence of amputation in frostbite injury with thrombolytic therapy. Arch Surg 2007;142:546-51.

[13] Sheridan RL, Goldstein MA, Stoddard Jr. FJ, Walker TG. Case records of the Massachusetts General Hospital. Case 41-2009. A 16-year-old boy with hypothermia and frostbite. N Engl J Med 2009;361(December (27)):2654-62.

[14] Wagner C, Pannucci CJ. Thrombolytic therapy in the acute management of frostbite injuries. Air Med J 2011;30(JanuaryFebryary (1)):39-44.

[15] Gross EA, Moore JC. Using thrombolytics in frostbite injury. J Emerg Trauma Shock 2012;5(July (3)):267-71.

[16] Ibrahim AE, Goverman J, Sarhane KA, Donofrio J, Walker TG, Fagan SP. The emerging role of tissue plasminogen activator in the management of severe frostbite. J Burn Care Res 2015;36 (March-April (2)):e62-6.

[17] Gonzaga T, Jenabzadeh K, Anderson CP, Mohr WJ, Endorf FW, Ahrenholz DH. Use of intra-arterial thrombolytic therapy for acute treatment of frostbite in 62 patients with review of thrombolytic therapy in frostbite. J Burn Care Res 2016;37(JulyAugust (4)):e323-34.

[18] Nygaard RM, Lacey AM, Lemere A, Dole M, Gayken JR, Lambert Wagner AL, Fey RM. Time matters in severe frostbite: assessment of limb/digit salvage on the individual patient level. J Burn Care Res 2017;38(January/Feburary (1)):53-9.

[19] Groechenig E. Treatment of frostbite with iloprost. Lancet 1994;344(8930):1152-3.

[20] Cauchy E, Cheguillaume B, Chetaille E. A controlled trial of a prostacyclin and rt-PA in the treatment of severe frostbite. $\mathrm{N}$ Engl J Med 2011;364(2):189-90.

[21] Poole A, Gauthier J. Treatment of severe frostbite with iloprost in northern Canada. CMAJ 2016;188(December (17-18)):1255-8.

[22] Nygaard RM, Whitley AB, Fey RM, Wagner AL. The Hennepin score: quantification of frostbite management efficacy. J Burn Care Res 2016;37(July-August (4)):e317-22.
[23] McCauley RL, Hing DN, Robson MC, Heggers JP. Frostbite injuries: a rational approach based on the pathophysiology. J Trauma 1983;23(February (2)):143-7.

[24] Cauchy E, Chetaille E, Marchand V, Marsigny B. Retrospective study of 70 cases of severe frostbite lesions: a proposed new classification scheme. Wilderness Environ Med 2001;12 (Winter (4)):248-55.

[25] Handford C, Buxton P, Russell K, Imray CE, McIntosh SE, Freer L, Cochran A, Imray CH. Frostbite a practical approach to hospital management. Extreme Physiol Med 2014;3 (April (22)):7.

[26] Catella-Lawson F, Reilly MP, Kapoor SC, Cucchiara AJ, DeMarco S, Tournier B, Vyas SN, FitzGerald GA. Cyclooxygenase inhibitors and the antiplatelet effects of aspirin. N Engl J Med 2001;345(December (25)):1809-17.

[27] Cauchy E, Marsigny B, Allamel G, Verhellen R, Chetaille E. The value of technetium 99 scintigraphy in the prognosis of amputation in severe frostbite injuries of the extremities: a retrospective study of 92 severe frostbite injuries. J Hand Surg Am 2000;25(September (5)):969-78.

[28] Millet JD, Brown RK, Levi B, Kraft CT, Jacobson JA, Gross MD, Wong KK. Frostbite: spectrum of imaging findings and guidelines for management. Radiographics 2016;36 (November-December (7)):2154-69.

[29] von Heimburg D, Noah EM, Sieckmann UP, Pallua N. Hyperbaric oxygen treatment in deep frostbite of both hands in a boy. Burns 2001;27(June (4)):404-8.

[30] Folio LR, Arkin K, Butler WP. Frostbite in a mountain climber treated with hyperbaric oxygen: case report. Mil Med 2007;172 (May (5)):560-3.

[31] Kemper TC, de Jong VM, Anema HA, van den Brink A, van Hulst RA. Frostbite of both first digits of the foot treated with delayed hyperbaric oxygen: a case report and review of literature. Undersea Hyperb Med 2014;41(January-February (1)):65-70.

[32] Bouwman DL, Morrison S, Lucas CE, Ledgerwood AM. Early sympathetic blockade for frostbite - is it of value? J Trauma 1980;20(September (9)):744-9.

[33] Taylor MS. Lumbar epidural sympathectomy for frostbite injuries of the feet. Mil Med 1999;164(August (8)):566-7.

[34] Chandran GJ, Chung B, Lalonde J, Lalonde DH. The hyperthermic effect of a distal volar forearm nerve block: a possible treatment of acute digital frostbite injuries? Plast Reconstr Surg 2010;126(September (3)):946-50.

[35] Miller MB, Koltai PJ. Treatment of experimental frostbite with pentoxifylline and aloe vera cream. Arch Otolaryngol Head Neck Surg 1995;121(June (16)):678-80.

[36] Purkayastha SS, Bhaumik G, Chauhan SK, Banerjee PK, Selvamurthy $W$. Immediate treatment of frostbite using rapid rewarming in tea decoction followed by combined therapy of pentoxifylline, aspirin \& vitamin C. Indian J Med Res 2002;116 (July):29-34.

[37] Stangl K, Laule M, Tenckhoff B, Stangl V, Gliech V, Dubel P, et al. Fibrinogen breakdown, long-lasting systemic fibrinolysis, and procoagulant activation during alteplase double-bolus regimen in acute myocardial infarction. Am J Cardiol 1998;81:841-7.

[38] White Harvey D, Van de Werf Frans JJ. Clinical cardiology: new frontiers thrombolysis for acute myocardial infarction. Circulation 1998;97:1632-46.

[39] Storey KB, Storey JM. Frozen and alive. Sci Am 1990;263 (December (6)):92-7. 